\title{
Biomarkers in post-reperfusion syndrome after acute lower limb ischaemia
}

\author{
Stefano de Franciscis ${ }^{1,2}$, Giovanni De Caridi ${ }^{3}$, Mafalda Massara ${ }^{3}$, Francesco Spinelli ${ }^{3}$, Luca Gallelli ${ }^{4}$, \\ Gianluca Buffone ${ }^{1}$, Francesco G Caliò ${ }^{5}$, Lucia Butrico ${ }^{2}$, Raffaele Grande ${ }^{2}$ \& Raffaele Serra ${ }^{1,2}$ \\ 1 Interuniversity Center of Phlebolymphology (CIFL), University Magna Graecia of Catanzaro, Catanzaro, Italy \\ 2 Department of Medical and Surgical Sciences, University Magna Graecia of Catanzaro, Catanzaro, Italy \\ 3 Cardiovascular and Thoracic Department, University of Messina, Messina, Italy \\ 4 Department of Health Sciences, University Magna Graecia of Catanzaro, Catanzaro, Italy \\ 5 Unit of Vascular Surgery, S. Anna Hospital, Catanzaro, Italy
}

\section{Key words}

Acute limb ischaemia; Cytokines; MMP; NGAL; Post-reperfusion syndrome

\section{Correspondence to}

Prof. R Serra, MD, PhD

Department of Medical and Surgical Science University Magna Graecia of Catanzaro

Viale Europa, Germaneto

Catanzaro 88100

Italy

E-mail: rserra@unicz.it de Franciscis S, De Caridi G, Massara M, Spinelli F, Gallelli L, Buffone G, Caliò FG, Butrico L, Grande R, Serra R. Biomarkers in post-reperfusion syndrome after acute lower limb ischaemia. Int Wound J 2014; doi: 10.1111/iwj.12392

\section{Abstract}

Ischaemia reperfusion (I/R) injury refers to tissue damage caused when blood supply returns to the tissue after a period of ischaemia. Matrix metalloproteinases (MMPs), neutrophil gelatinase-associated lipocalin (NGAL) and cytokines are biomarkers involved in several vascular complications. The aim of this study was to evaluate the role of MMPs, NGAL and inflammatory cytokines in I/R syndrome. We conducted an open label, multicentric, parallel group study, between January 2010 and December 2013. Patients with acute limb ischaemia were enrolled in this study and were divided into two groups: (i) those subjected to fasciotomy and (ii) those not subjected to fasciotomy, according to the onset of compartment syndrome. Plasma and tissue values of MMPs and NGAL as well as plasma cytokines were evaluated. MMPs, NGAL and cytokine levels were higher in patients with compartment syndrome. Biomarkers evaluated in this study may be used in the future as predictors of I/R injury severity and its possible evolution towards post-reperfusion syndrome.

\section{Introduction}

Acute limb ischaemia (ALI) is a common and often severe clinical event (1). Its main causes are embolisation, in situ arterial thrombosis, acute graft occlusion $(2,3)$ or very infrequent complications of arterovenous fistula for haemodialysis (4).

ALI is related to a high frequency of mortality, particularly when the treatment is delayed (5-7).

Commonly, the first line of treatment is the reestablishment of blood flow, since it could be related with the development of several complications, for example, ischaemia reperfusion (I/R) syndrome $(8,9)$.

I/R syndrome has essentially two components: (i) local activation and adhesion of polymorphonuclear cells (PNMs) and platelets, release of inflammatory mediators, that is, tumour necrosis factor-alfa (TNF- $\alpha$ ), interleukin-1 beta (IL-1 $\beta$ ) and interleukin-6 (IL-6), activation of matrix metalloproteinases (MMPs), generation of free radical oxygen, cell death and increased tissue pressure with capillary occlusion (compartment syndrome) and increased ischaemic lesion; (ii) systemic - called post-reperfusion syndrome (PRS), that

\section{Key Messages}

- ischaemia reperfusion (I/R) syndrome is a potentially devastating condition associated with many surgical treatments and plays a critical role in limb salvage procedures and in patients' functional outcomes

- several studies have shown that I/R injury is related to endothelial cells (ECs) and extracellular matrix (ECM) activation. ECM activation is regulated mainly by matrix metalloproteinases (MMPs), which may also modulate the actions of inflammatory cytokines

- in this study we evaluated the role of MMPs and inflammatory cytokines in patients with $\mathrm{I} / \mathrm{R}$ syndrome of the lower limbs and their correlation with the main biochemical parameters 
- our experience confirmed the central role of inflammation in I/R syndrome and the association between the main inflammatory cytokines and MMPs

is, secondary failure of organs and tissues related to the progression of the reperfusion injury (10-12).

MMPs are proteolytic enzymes that degrade the extracellular matrix (ECM) and play a role in both vascular (13-25) and non-vascular diseases. Furthermore, it has been documented that MMPs are significantly involved in I/R injury in the lung, heart, brain and kidney (26). Neutrophil gelatinase-associated lipocalin (NGAL) is an acute-phase protein and its expression is upregulated under diverse conditions; it also cooperates with MMPs in degrading ECM (15-19,23).

The aim of this article was to evaluate the role of MMPs, NGAL and inflammatory cytokines in patients with ALI, and their correlation with I/R syndrome and the main biochemical parameters.

\section{Materials and methods}

\section{Study design}

We conducted an open label, multicentric, parallel group study, between January 2010 and December 2013. This study was approved by the Institutional Review Board-Independent Ethics Committee (IRB-IEC). Before the beginning of the study, all participants were informed about the aim, procedures, risks and benefits of the study and a written informed consent was obtained from them.

\section{Patients}

Patients with acute embolism or thrombosis of the distal artery presenting with a diagnosis of acute ischaemia of the lower limbs were enrolled in this study.

Signs of an acute arterial occlusion were considered: slightly pale limbs; absence of proximal or distal pulses on affected limbs examined through Doppler ultrasound; decrease in active and passive movements of the limbs as well as peripheral reflexes; and impairment of sensation to tactile, thermal and nociceptive stimuli. Morphological graduation of the lesions was performed non-invasively through duplex ultrasound and invasively during angiography.

ALI was evaluated in accordance with the Rutherford classification (27).

Enrolled patients were divided into two groups: group I - patients who required fasciotomy, and group II - patients who did not require fasciotomy, according to the onset of the compartment syndrome. We defined early compartment syndrome (ECS) as the onset of compartment syndrome within 2-6 hours after the revascularisation procedure and late compartment syndrome (LCS) as the onset of compartment syndrome over 12 hours after the revascularisation procedure $(27,28)$.

Fasciotomy has been advocated in patients with compromised blood flow for 4-6hours, prolonged hypotension, combined arterial and venous injuries, distal limb swelling and absolute compartment pressures of $30 \mathrm{mmHg}$ or higher, $40-55 \mathrm{mmHg}$, or $55 \mathrm{mmHg}$ or higher (28).

Patients undergoing endovascular treatment with local thrombolysis as well as patients who had undergone unsuccessful surgical treatment resulting in amputation of an extremity were excluded. Patients without the possibility of adequate surgical revascularisation, resulting in limb loss, were excluded from this study because of failing evidence of reperfusion marker levels.

\section{MMPs and NGAL evaluation in plasma and tissues}

Blood samples were collected at the time of admission $(T=0)$, 6 hours $(T=1), 24$ hours $(T=2), 3$ days $(T=3)$ and 1 week $(T=4)$ after the revascularisation. Moreover, tissue biopsies were taken at the time of fasciotomy.

Samples were frozen and then analysed using enzyme-linked immunosorbent assay (ELISA) test and Western Blotting to evaluate both MMPs and NGAL levels in plasma and tissues, respectively.

\section{ELISA test}

The ELISA test was performed as previously reported (13-25). A commercially available sandwich ELISA kit with MMP-1, $-2,-3$ and -9 monoclonal antibodies (Biotrak Human ELISA System, Amersham Pharmacia Biotech, Buckinghamshire, UK) was used to determine plasma MMP levels. The soluble concentrations of NGAL were quantified using a commercial ELISA kit (Bioporto diagnostics, Hellerup, Denmark), in agreement with the manufacturer's instructions. For both MMPs and NGAL, results were evaluated relative to a control group of healthy patients.

\section{Western blot evaluation}

During fasciotomy, tissues were taken and lysed in $2 \mathrm{ml}$ of tissue protein extraction reagent $(25 \mathrm{mM}$ Bicine, $150 \mathrm{mM}$ sodium chloride $\mathrm{pH}$ 7.6; Thermo Scientific, Waltham, MA). Immunoblotting was performed using anti MMP-1, -2, -3, -9 and anti-NGAL monoclonal antibodies as previously described $(13,21)$. All experiments were performed in triplicate. The pectineus muscle and the anterior tibial muscle (injured samples) were the sites of intraoperative biopsies.

\section{Cytokine analysis}

An ELISA (Human ELISA System, Amersham Pharmacia Biotech) kit was used to determine the plasma concentrations of IL-1, IL-6, IL- 8 and TNF- $\alpha$, as previously described $(12,17,29-31)$.

\section{Biochemical evaluation}

Serum concentrations of creatine kinase (CK), lactate dehydrogenase (LDH), alanine aminotransferase (ALT), aspartate aminotransferase (AST), potassium and calcium ions $\left(\mathrm{K}^{+}\right.$and 
$\mathrm{Ca}^{++}$), blood urea nitrogen (BUN), creatinine, c-reactive protein (CRP), serum amylase and lipase, fibrinogen and albuminuria, and activated partial thromboplastin time (aPTT) were evaluated in all patients through the period of study (from $T=0$ to $T=4)$.

\section{Statistical analysis}

To consider a difference in the response of matched pairs distributed with a standard deviation of 5 and a mean response of 2 , we needed to study 55 pairs of subjects so as to be reject the null hypothesis that this response difference was zero with probability (power $>83 \%$, alpha $0 \cdot 05$, two-tailed).

The mean, standard deviation and range were reported for the continuous variables, whereas the counts described the categorical variables. Data were checked for normality using the Kolmogorove-Smirnov test. The Student's $t$-test and the $\chi(2)$ test were used when appropriate to test the significance of the differences. The analysis of variance (ANOVA) was used to evaluate the differences between multiple means. Once it had been determined that differences existed, a Bonferroni test was used to determine which means differed. Pearson's test was used to evaluate the correlation between biochemical markers and plasma levels of MMPs and of NGAL. All data were expressed as mean \pm standard error of the mean (SEM). A $P$-value of less than 0.05 was considered statistically significant. The SPSS (SPSS Inc., Chicago, IL) and G*Power (Institut für Experimentelle Psychologie, Heinrich Heine Universität, Dusseldorf, Germany) software were used for the statistical analyses.

\section{Results}

For this study, we enrolled 142 patients (96 men and 46 women, mean age $70 \cdot 3 \pm 7 \cdot 1$ years) with clinical signs of an acute arterial occlusion. The patients' characteristics are shown in Table 1.

ALI was most commonly related to atrial fibrillation (82 patients). Patent foramen ovale with contralateral embolism was found in nine cases. The time of limb ischaemia before surgical treatment was 2-48 hours. Time of limb ischaemia was not a significant predictor of clinically relevant compartment syndrome. The patients' history revealed that 53 of them suffered from chronic limb ischaemia (CLI): 19 in Fontaine IIa and 21 in Fontaine IIb, and 13 in Fontaine III.

The 142 patients were divided into two groups:

- Group I: patients (with compartment syndrome) requiring fasciotomy $(n=7 ; 4.93 \%)$.

- Group II: patients (without compartment syndrome) not requiring fasciotomy $(n=145 ; 95 \cdot 07 \%)$.

Moreover, 70 healthy volunteers were enrolled in this study and represented the control group (group III).

The laboratory findings documented higher levels of all evaluated biochemical values in group I and group II relative to group III $(P<0 \cdot 01$; data not shown); moreover, the laboratory results were higher in group I relative to group II $(P<0 \cdot 01$; Table 2).
Table 1 Patients' characteristics

\begin{tabular}{|c|c|c|c|}
\hline & $\begin{array}{l}\text { Patients with } \\
\text { fasciotomy } \\
(n=7)\end{array}$ & $\begin{array}{c}\text { Patients } \\
\text { without fasciotomy } \\
\qquad(n=135)\end{array}$ & $P$ value \\
\hline $\operatorname{Sex}(M / F)$ & $5 / 2$ & $91 / 44$ & 0.824 \\
\hline \multicolumn{4}{|l|}{ Comorbidity } \\
\hline Hypertension & 4 & 98 & 0.735 \\
\hline Smoking & 5 & 89 & 0.764 \\
\hline Diabetes mellitus & 3 & 71 & $0 \cdot 615$ \\
\hline Atrial fibrillation & 4 & 76 & 0.965 \\
\hline Ischaemic heart disease & 5 & 82 & 0.571 \\
\hline Cerebrovascular disease & 3 & 62 & 0.874 \\
\hline Anaemia & 2 & 61 & 0.388 \\
\hline Renal insufficiency & 5 & 96 & 0.986 \\
\hline Hepatic insufficiency & 4 & 53 & 0.346 \\
\hline Malignancy & 2 & 40 & 0.952 \\
\hline Dyslipidemia & 6 & 101 & 0.514 \\
\hline Hyperuricemia & 5 & 92 & 0.855 \\
\hline Obesity & 6 & 64 & 0.048 \\
\hline CLI & 4 & 49 & 0.266 \\
\hline \multicolumn{4}{|l|}{ Medication } \\
\hline Ace inhibitors & 4 & 86 & 0.725 \\
\hline B-blockers & 5 & 83 & 0.597 \\
\hline Vasodilators & 5 & 69 & 0.294 \\
\hline Lipid-lowering agents & 6 & 77 & 0.133 \\
\hline $\begin{array}{l}\text { Thrombocyte aggregation } \\
\text { inhibitors }\end{array}$ & 7 & 90 & 0.064 \\
\hline Warfarin & 3 & 62 & 0.874 \\
\hline \multicolumn{4}{|l|}{ Cause of occlusion } \\
\hline \multicolumn{4}{|l|}{ Embolism } \\
\hline Aortoiliac embolism & 2 & 53 & 0.571 \\
\hline Cardiac embolism & 3 & 57 & 0.973 \\
\hline \multicolumn{4}{|l|}{ Thrombosis } \\
\hline Occluded venous graft & 0 & 6 & 0.568 \\
\hline Occluded synthetic graft & 0 & 9 & 0.480 \\
\hline Occluded stent & 1 & 6 & $0 \cdot 240$ \\
\hline Peripheral aneurysm & 1 & 4 & $0 \cdot 113$ \\
\hline \multicolumn{4}{|l|}{ Distribution by severity } \\
\hline Rutherford I & 0 & 9 & 0.480 \\
\hline Rutherford Ila & 2 & 103 & 0.005 \\
\hline Rutherford IIb & 5 & 23 & 0.0004 \\
\hline Rutherford III & 0 & 0 & - \\
\hline
\end{tabular}

CLI, chronic limb ischaemia; F, female; $M$, male.

In group I, five of seven patients $(71.43 \%)$ manifested an ECS and were treated with fasciotomy within 6 hours; of these, one patient $(20.00 \%)$ died of multi-organ failure; two of the seven patients $(28.57 \%)$ showed LCS and were treated with fasciotomy within 24-36 hours; 1 patient (50.00\%) died during the follow-up period (Table 1).

The ELISA test revealed that plasma levels of MMP-1, -2, -3 and -9 were higher in patients subjected to fasciotomy (group I) relative to patients not subjected to it (group II) $(P<0 \cdot 01$, Table 3). The Western blot evaluation also revealed an increased expression of active MMP-1, -2, -3, -9 and NGAL in tissues of group I patients relative to patients enrolled in group II $(P<0 \cdot 01$, data not shown $)$

Both plasma and tissue values of MMPs and NGAL as well as biochemical values decreased in a time-dependent pattern after fasciotomy (see Table 3), with an initial decrease after 24-36 hours and a normalisation after 1 week; in patients with 
Table 2 Laboratory findings recorded in enrolled patients after reperfusion. Results represent mean \pm standard deviation

\begin{tabular}{|c|c|c|c|}
\hline \multirow[b]{2}{*}{ Laboratory measurements } & \multicolumn{2}{|c|}{ Mean serum Levels after reperfusion } & \multirow[b]{2}{*}{$P$ value } \\
\hline & Group I & Group II & \\
\hline Creatine kinase (CK) (nr 24-195 U/l) & $103765 \pm 1135$ & $75321 \pm 932$ & $<0.01$ \\
\hline Lactate dehydrogenase (LDH) (nr 110-120 U/l) & $29004 \pm 850$ & $21223 \pm 784$ & $<0.01$ \\
\hline Alanine aminotransferase (nr 5-45 U/L) & $8015 \pm 335$ & $5766 \pm 178$ & $<0.01$ \\
\hline Aspartate aminotransferase (nr 5-45 U/L) & $6280 \pm 548$ & $4399 \pm 224$ & $<0.01$ \\
\hline Potassium ions (nr 3.5-4.5 meq/l) & $5 \cdot 3 \pm 0.9$ & $4.6 \pm 0.7$ & $<0.01$ \\
\hline Calcium ions ( $\mathrm{nr} 9-10 \mathrm{mg} / \mathrm{dl}$ ) & $12 \pm 1 \cdot 3$ & $9 \cdot 7 \pm 1 \cdot 5$ & $<0.01$ \\
\hline Blood urea nitrogen $(\mathrm{nr} 2.5-7.1 \mathrm{mmol} / \mathrm{l})$ & $9 \cdot 3 \pm 1 \cdot 5$ & $7 \cdot 8 \pm 1 \cdot 3$ & $<0.05$ \\
\hline Creatinine (nr $60-110 \mu \mathrm{M} / \mathrm{l})$ & $254 \pm 18 \cdot 3$ & $151 \pm 15 \cdot 2$ & $<0.01$ \\
\hline C-reactive protein (CRP) (nr) & $5 \cdot 9 \pm 0.8$ & $3.5 \pm 0.35$ & $<0.01$ \\
\hline Serum amylase (nr 30-100 U/l) & $88 \pm 11$ & $64 \pm 13$ & $<0.01$ \\
\hline Serum lipase (nr 10-60 U/l) & $76 \pm 14$ & $46 \pm 15$ & $<0.01$ \\
\hline Albuminuria ( $\mathrm{nr}<30 \mathrm{mg}$ of albumin per 24 hours) & $673 \pm 42$ & $294 \pm 11$ & $<0.01$ \\
\hline Fibrinogen (nr 200-400 mg/dl) & $989 \pm 84$ & $632 \pm 55$ & $<0.01$ \\
\hline Activated partial thromboplastin time (aPTT) ( $\mathrm{nr} 30-40$ seconds) & $56 \pm 7 \cdot 6$ & $42 \pm 7 \cdot 2$ & $<0.01$ \\
\hline
\end{tabular}

nr, normal range.

Table 3 MMP plasma values obtained using ELISA test in patients subjected to fasciotomy (group I), in patients not subjected to fasciotomy (group II) and in control patients (group III). Results represent the mean \pm standard deviation of values detected in enrolled patients

\begin{tabular}{|c|c|c|c|c|c|}
\hline & \multicolumn{5}{|c|}{ At Time of Admission } \\
\hline & MMP1 & MMP2 & MMP3 & MMP9 & NGAL \\
\hline Group I & $5 \cdot 2 \pm 0 \cdot 4$ & $1025 \pm 92 \cdot 3$ & $17 \cdot 2 \pm 2 \cdot 1$ & $425 \pm 41 \cdot 2$ & $195 \pm 33 \cdot 4$ \\
\hline Group II & $4 \cdot 1 \pm 0 \cdot 3$ & $750 \pm 58 \cdot 7$ & $11 \cdot 5 \pm 2 \cdot 3$ & $315 \pm 32 \cdot 5$ & $145 \pm 25 \cdot 7$ \\
\hline Group III & $\begin{array}{l}2 \cdot 9 \pm 0.7 \\
24-36 \text { ho }\end{array}$ & $\begin{array}{l}478 \pm 19 \cdot 8 \\
\text { urs }\end{array}$ & $6 \cdot 9 \pm 1 \cdot 1$ & $54 \pm 11.5$ & $32 \pm 12 \cdot 3$ \\
\hline Group I & $4 \cdot 4 \pm 0.2$ & $755 \pm 85 \cdot 1$ & $12 \cdot 1 \pm 1 \cdot 9$ & $220 \pm 36 \cdot 3$ & $91 \pm 21 \cdot 2$ \\
\hline Group II & $3 \cdot 3 \pm 0 \cdot 4$ & $630 \pm 44 \cdot 8$ & $9 \cdot 7 \pm 1 \cdot 4$ & $132 \pm 22 \cdot 2$ & $73 \pm 19 \cdot 4$ \\
\hline Group III & $\begin{array}{l}2 \cdot 8 \pm 0 \cdot 9 \\
1 \text { week }\end{array}$ & $475 \pm 19 \cdot 5$ & $6 \cdot 8 \pm 1 \cdot 0$ & $56 \cdot 2 \pm 12 \cdot 3$ & $34 \cdot 8 \pm 12 \cdot 7$ \\
\hline Group I & $2 \cdot 9 \pm 0 \cdot 2$ & $480 \pm 20 \cdot 3$ & $7 \cdot 2 \pm 1 \cdot 7$ & $56 \cdot 3 \pm 12 \cdot 1$ & $34 \cdot 9 \pm 13 \cdot 0$ \\
\hline Group II & $2 \cdot 8 \pm 0 \cdot 6$ & $478 \pm 20 \cdot 1$ & $6 \cdot 8 \pm 0 \cdot 8$ & $55 \cdot 7 \pm 12 \cdot 2$ & $35 \cdot 3 \pm 12 \cdot 6$ \\
\hline Group III & $2 \cdot 8 \pm 0.3$ & $476 \pm 19 \cdot 7$ & $6 \cdot 9 \pm 1 \cdot 2$ & $55 \cdot 1 \pm 12 \cdot 6$ & $33 \cdot 1 \pm 12 \cdot 4$ \\
\hline
\end{tabular}

ELISA, enzyme-linked immunosorbent assay; MMP, matrix metalloproteinases; NGAL, neutrophil gelatinase-associated lipocalin.

LCS, biochemical values decreased initially after 36 hours. Finally, using the Pearson's test we documented a significant correlation between MMP levels and biochemical parameters $(P<0 \cdot 01)$.

\section{Discussion}

In this study, we evaluated the role of MMPs and inflammatory cytokines in patients with I/R syndrome of the lower limbs and their correlation with the main biochemical parameters.

Several studies have shown that $\mathrm{I} / \mathrm{R}$ injury is related to endothelial cells (ECs) (32) and ECM activation: ECs activate both complement and coagulation systems and induce the recruitment of proinflammatory cells, which progressively induce the no-reflow phenomenon (33). A dysfunction of both sodium-potassium ATPase and calcium-sodium exchanger is also involved; elevated levels of free calcium interact with actin, myosin and cellular proteases, resulting in skeletal muscle fibre necrosis. These events are amplified by reperfusion (34). Local complications of I/R injury may also result in amputation or severe dysfunction in the salvaged limbs (34). I/R injury of an extensive muscle tissue mass and the sensitive vascular tissues and endothelium often leads to systemic complications, a phenomenon called PRS (35). I/R injury is characterised by massive oedema often requiring fasciotomy, which increases fluid requirements and may cause shock; myoglobin, potassium, lactate and microthrombi release from the damaged skeletal muscle into the systemic circulation can cause renal failure, arrhythmias and, eventually, death (36).

In agreement with these data, in our article we reported that three patients died after fasciotomy, documenting that fasciotomy is usually performed in patients with impaired clinical conditions.

Several studies have shown a 'common inflammatory pathway' between lower limb injuries, such as I/R syndrome, and systemic organs: mediators of the local response to IR injury can also have systemic effects and the organs become the target tissues of a systemic inflammatory response process. Acute lung injury, myocardial dysfunction, acute renal failure, hepatic failure and pancreatitis contribute significantly to the morbidity and mortality associated with I/R syndrome (36).

Our experience confirms the central role of inflammation in $\mathrm{I} / \mathrm{R}$ syndrome. We have shown the association between the main inflammatory cytokines and MMPs. In our study, patients with arterial thrombosis showed baseline elevated levels of MMP-1, -2, -3, -9 and NGAL at the time of admission, compared to healthy volunteers; this is attributable to a pre-existent chronic inflammatory vascular condition, as previously described $(14-21,37)$. Moreover, in patients treated with fasciotomy because of compartment syndrome, higher levels of MMP-1, -2, -3, -9 and NGAL were detected.

In accordance with the literature data (38-41), our results document the association between inflammation and the main biochemical functional parameters.

Furthermore, we have highlighted the significant association between high biochemical parameter levels, which indicate damaged organs, and MMP-1, -2, -3 and -9; another important 
aspect was that the biochemical parameters were much higher in patients who suffered the most serious complications of $I / R$ syndrome, such as respiratory, renal and heart failure, than in patients who did not develop severe complications, and their levels of MMP-9 were more elevated and associated with NGAL expression. NGAL can be considered as a parameter associated with an increased severity of the disease.

$\mathrm{I} / \mathrm{R}$ injury is a potentially devastating condition associated with many diseases treated by surgery and plays a critical role in limb salvage procedures and in patients' functional outcomes. The authors have postulated that pharmacologic modulation of inflammatory cytokines is a promising strategy to prevent I/R syndrome (29). Our study focalised the pivotal role of MMPs: MMPs and NGAL could in the future be used as biological markers of I/R injury severity and its possible evolution towards more severe pathological stages such as PRS.

\section{Acknowledgement}

The authors declare that they have no competing interests. This work received no funding.

\section{References}

1. Norgren L, Hiatt WR, Dormandy JA, Nehler MR, Harris KA, Fowkes FG, TASC II Working Group, Bell K, Caporusso J, Durand-Zaleski I, Komori K, Lammer J, Liapis C, Novo S, Razavi M, Robbs J, Schaper N, Shigematsu H, Sapoval M, White C, White J, Clement D, Creager M, Jaff M, Mohler E 3rd, Rutherford RB, Sheehan P, Sillesen H, Rosenfield K. Inter-society consensus for the management of peripheral arterial disease (TASC II). Eur J Vasc Endovasc Surg 2007;33(1 Suppl):S1-75.

2. Klonaris C, Georgopoulos S, Katsargyris A, Tsekouras N, Bakoyiannis C, Giannopoulos A, Bastounis E. Changing patterns in the etiology of acute lower limb ischemia. Int Angiol 2007;26:49-52.

3. Mutirangura P, Ruangsetakit C, Wongwanit C, Sermsathanasawadi $\mathrm{N}$, Chinsakchai K. Clinical differentiation between acute arterial embolism and acute arterial thrombosis of the lower extremities. J Med Assoc Thai 2009;92:891-7.

4. De Caridi G, Massara M, Benedetto F, Tripodi P, Spinelli F, David A, Grande R, Butrico L, Serra R, de Franciscis S. Adjuvant spinal cord stimulation improves wound healing of peripheral tissue loss due to steal syndrome of the hand: clinical challenge treating a difficult case. Int Wound J 2014; doi: 10.1111/iwj.12233.

5. Biancari F. Meta-analysis of the prevalence, incidence and natural history of critical limb ischemia. J Cardiovasc Surg (Torino) 2013;54:663-9.

6. Henke PK. Contemporary management of acute limb ischemia: factors associated with amputation and in-hospital mortality. Semin Vasc Surg 2009;22:34-40.

7. Mutirangura P, Ruangsetakit C, Wongwanit C, Sermsathanasawadi N, Chinsakchai K. Acute arterial embolism of the lower extremities: impact of 24-hour duration on the outcome of management. $\mathrm{J} \mathrm{Med}$ Assoc Thai 2008;91:1360-7.

8. Baril DT, Patel VI, Judelson DR, Goodney PP, McPhee JT, Hevelone ND, Cronenwett JL, Schanzer A, Vascular Study Group of New England. Outcomes of lower extremity bypass performed for acute limb ischemia. J Vasc Surg 2013;58:949-56.

9. Serra R, Ciranni S, Molinari V, Mastroroberto P, de Franciscis S. Fatal early peripheral post-reperfusion syndrome and the role of cutaneous signs. Int Wound J 2014; doi: 10.1111/iwj.12247.

10. Eliason JL, Wakefield TW. Metabolic consequences of acute limb ischemia and their clinical implications. Semin Vasc Surg 2009;22:29-33.
11. Serra R, Grande R, Buffone G, Scarcello E, Tripodi F, Rende P, Gallelli L, de Franciscis S. Effects of glucocorticoids and TNF-alfa inhibitors on both clinical and molecular parameters in patients with Takayasu arteritis. J Pharmacol Pharmacother 2014;5:193-6.

12. Siniscalchi A, Gallelli L, Malferrari G, Pirritano D, Serra R, Santangelo E, De Sarro G. Cerebral stroke injury: the role of cytokines and brain inflammation. J Basic Clin Physiol Pharmacol 2014;25:131-7.

13. Serra R, Buffone G, Costanzo G, Montemurro R, Scarcello E, Stillitano DM, Damiano R, de Franciscis S. Altered metalloproteinase-9 expression as the least common denominator between varicocele, inguinal hernia and chronic venous disorders. Ann Vasc Surg 2014;28:705-9.

14. Amato B, Coretti G, Compagna R, Amato M, Buffone G, Gigliotti D, Grande R, Serra R, de Franciscis S. Role of matrix metalloproteinases in non-healing venous ulcers. Int Wound J 2013; doi: 10.1111/iwj.12181[Epub ahead of print].

15. Serra R, Buffone G, Falcone D, Molinari V, Scaramuzzino M, Gallelli L, de Franciscis S. Chronic venous leg ulcers are associated with high levels of metalloproteinases-9 and neutrophil gelatinase-associated lipocalin. Wound Repair Regen 2013;21:395-401.

16. Serra R, Grande R, Buffone G, Gallelli L, de Franciscis S. The effects of minocycline on extracellular matrix in patients with chronic venous leg ulcers. Acta Phlebol 2013;14:99-107.

17. Busceti MT, Grande R, Amato B, Gasbarro V, Buffone G, Amato M, Gallelli L, Serra R, de Franciscis S. Pulmonary embolism, metalloproteinases and neutrophil gelatinase associated lipocalin. Acta Phlebol 2013;14:115-21.

18. de Franciscis S, Mastroroberto P, Gallelli L, Buffone G, Montemurro $\mathrm{R}$, Serra R. Increased plasma levels of metalloproteinase-9 and neutrophil gelatinase-associated lipocalin in a rare case of multiple artery aneurysm. Ann Vasc Surg 2013;27:1185.e5-7.

19. Serra R, Grande R, Montemurro E, Butrico L, Caliò FG, Mastrangelo D, Scarcello E, Gallelli L, Buffone G, de Franciscis S. The role of matrix metalloproteinases and neutrophil gelatinase-associated lipocalin in central and peripheral arterial aneurysms. Surgery 2014. In press; doi: 10.1016/j.surg.2014.06.008.

20. de Franciscis S, Gallelli L, Battaglia L, Molinari V, Montemurro R, Stillitano DM, Buffone G, Serra R. Cilostazol prevents foot ulcers in diabetic patients with peripheral vascular disease. Int Wound J 2013; doi: 10.1111/iwj.12085.

21. Serra R, Gallelli L, Buffone G, Molinari V, Stillitano DM, Palmieri $\mathrm{C}$, de Franciscis S. Doxycycline speeds up healing of chronic venous ulcers. Int Wound J 2013; doi: 10.1111/iwj.12077.

22. Serra R, Grande R, Butrico L, Buffone G, Caliò FG, Squillace A, Rizzo BA, Massara M, Spinelli F, Ferrarese AG, de Caridi G, Gallelli L, de Franciscis S. Effects of a new nutraceutical substance on clinical and molecular parameters in patients with chronic venous ulceration. Int Wound J 2014; doi: 10.1111/iwj.12240.

23. Serra R, Gallelli L, Conti A, De Caridi G, Massara M, Spinelli F, Buffone G, Caliò FG, Amato B, Ceglia S, Spaziano G, Scaramuzzino L, Ferrarese AG, Grande R, de Franciscis S. The effects of Sulodexide on both clinical and molecular parameters in patients with mixed arterial and ulcers of lower limbs. Drug Des Devel Ther 2014;8:1-9.

24. Serra R, Grande R, Buffone G, Molinari V, Perri P, Perri A, Amato B, Colosimo M, de Franciscis S. Extracellular matrix assessment of infected chronic venous leg ulcers: role of metalloproteinases and inflammatory cytokines. Int Wound J 2014; doi: 10.1111/iwj.12225.

25. Serra R, Grande R, Gallelli L, Rende P, Scarcello E, Buffone G, Caliò FG, Gasbarro V, Amato B, de Franciscis S. Carotid body paragangliomas and matrix metalloproteinases. Ann Vasc Surg 2014;28:1665-70.

26. Kunugi S, Shimizu A, Kuwahara N, Du X, Takahashi M, Terasaki Y, Fujita E, Mii A, Nagasaka S, Akimoto T, Masuda Y, Fukuda Y. Inhibition of matrix metalloproteinases reduces ischemia-reperfusion acute kidney injury. Lab Invest 2011;91:170-80.

27. Rutherford RB, Baker JD, Ernst C, Johnston KW, Porter JM, Ahn $\mathrm{S}$, Jones DN. Recommended standards for reports dealing with lower extremity ischemia: revised version. J Vasc Surg 1997;26:517-38. 
28. Gourgiotis S, Villias C, Germanos S, Foukas A, Ridolfini MP. Acute limb compartment syndrome: a review. J Surg Educ 2007;64:178-86.

29. Gallelli L, Pelaia G, Fratto D, Muto V, Falcone D, Vatrella A, Curto LS, Renda T, Busceti MT, Liberto MC, Savino R, Cazzola M, Marsico SA, Maselli R. Effects of budesonide on P38 MAPK activation, apoptosis and IL-8 secretion, induced by TNF-alpha and Haemophilus influenzae in human bronchial epithelial cells. Int J Immunopathol Pharmacol 2010;23:471-9.

30. Pelaia G, Cuda G, Vatrella A, Gallelli L, Fratto D, Gioffrè V, D'Agostino B, Caputi M, Maselli R, Rossi F, Costanzo FS, Marsico SA. Effects of hydrogen peroxide on MAPK activation, IL-8 production and cell viability in primary cultures of human bronchial epithelial cells. J Cell Biochem 2004;93:142-52.

31. Gallelli L, Galasso O, Falcone D, Southworth S, Greco M, Ventura V, Romualdi P, Corigliano A, Terracciano R, Savino R, Gulletta E, Gasparini G, De Sarro G. The effects of nonsteroidal anti-inflammatory drugs on clinical outcomes, synovial fluid cytokine concentration and signal transduction pathways in knee osteoarthritis. A randomised open label trial. Osteoarthritis Cartilage 2013;21:1400-8.

32. Chappell D, Heindl B, Jacob M, Annecke T, Chen C, Rehm M, Conzen $\mathrm{P}$, Becker BF. Sevoflurane reduces leukocyte and platelet adhesion after ischemia-reperfusion by protecting the endothelial glycocalyx. Anesthesiology 2011;115:483-91.

33. Abela $\mathrm{CB}$, Homer-Vanniasinkham S. Clinical implications of ischaemia-reperfusion injury. Pathophysiology 2003;9:229-40.

34. Szijártó A, Turóczi Z, Szabó J, Turóczi Z, Szabó J, Kaliszky P, Gyurkovics E, Arányi P, Regáli L, Harsányi L, Lotz G. Rapidly progressing fatal reperfusion syndrome caused by acute critical ischemia of the lower limb. Cardiovasc Pathol 2013;22:493-500.
35. Cruz CP, Eidt JF, Capps C, Kirtley L, Moursi MM. Major lower extremity amputations at a Veterans Affairs hospital. Am J Surg 2003;186:449-54.

36. Klausner JM, Paterson IS, Kobzik L, Valeri CR, Shepro D, Hechtman HB. Oxygen free radicals mediate ischemia-induced lung injury. Surgery 1989;105(2 Pt 1):192-9.

37. Bu DX, Hemdahl AL, Gabrielsen A, Fuxe J, Zhu C, Eriksson P, Yan ZQ. Induction of neutrophil gelatinase-associated lipocalin in vascular injury via activation of nuclear factor-kappaB. Am J Pathol 2006; 169:2245-53.

38. Shahar E, Attias U, Savulescu D, Genizin J, Gavish M, Nagler R. Oxidative stress, metalloproteinase and LDH in children with intractable and non-intractable epilepsy as reflected in salivary analysis. Epilepsy Res 2014;108:117-24.

39. Zhang X, Zhang T, Wu J, Yu X, Zheng D, Yang F, Li T, Wang L, Zhao Y, Dong S, Zhong X, Fu S, Xu CQ, Lu F, Zhang WH. Calcium sensing receptor promotes cardiac fibroblast proliferation and extracellular matrix secretion. Cell Physiol Biochem 2014;33:557-68.

40. Misra S, Shergill U, Yang B, Janardhanan R, Misra KD. Increased expression of HIF-1alpha, VEGF-A and its receptors, MMP-2, TIMP-1, and ADAMTS-1 at the venous stenosis of arteriovenous fistula in a mouse model with renal insufficiency. $J$ Vasc Interv Radiol 2010;21:1255-61.

41. Dinh W, Füth R, Scheffold T, Bansemir L, Köhler T, Lapp H, Bufe A, Nickl W, Stasch JP, Lankisch M. Increased serum levels of tissue inhibitor of metalloproteinase-1 in patients with acute myocardial infarction. Int Heart J 2009;50:421-31. 